\title{
The Effect of Dynamic Assessment on EFL Reading Comprehension in Different Proficiency Levels
}

\section{PARVIZ AJIDEH}

University of Tabriz, Iran

\section{NAVA NOURDAD}

Iran

\author{
Bio Data: \\ Dr. Parviz Ajideh is an Associate Professor in the English Department \\ at Tabriz University in the Islamic Republic of Iran. His research \\ interests include reading, testing, and translation.
}

Nava Nourdad is a Ph.D. candidate at university of Tabriz. Currently she is completing her dissertation. Her research interests include Testing, Reading and ESP.

\begin{abstract}
The present study aimed at investigating the effect of dynamic assessment on EFL learners' reading comprehension in different proficiency levels. 197 Iranian university students participated in six groups of this study. The design of the research was quasiexperimental. The results of MANOVA test revealed that while dynamic assessment had improving immediate and delayed effect on reading comprehension of learners in all proficiency levels the proficiency groups did not differ significantly in their taking advantage of this kind of assessment.
\end{abstract}

Keywords: Dynamic assessment, Non-dynamic assessment, Sociocultural theory, Zone of proximal development, Reading comprehension ability

\section{Introduction}

Language testing and assessment have always been influenced by changes in language teaching methods. Looking back into the history of language teaching the methods can be classified into three consequent categories of language-centered, learner-centered, and learning-centered methods. As Kumaravadivelu (2006, p. 121) clearly mentions to meet their learning-teaching principle requirements languagecentered and learner-centered pedagogists opted for a product-oriented syllabus. But later emerging learning-centered methods such as natural approach and communicational approach moved toward process-oriented approaches to language teaching (p.134). He also adds that 
Unlike the product-based syllabus, where the content of learning/teaching is defined in terms of linguistic features, the process-based syllabus defines it exclusively in terms of communicative activities. In other words, a learningcentered pedagogic syllabus constitutes an indication of learning tasks, rather than an index of language features, leaving the actual language to emerge from classroom interaction (p.144).

As expected such changes in language teaching orientation did not leave the assessment orientation untouched and along with teaching methods their corresponding testing or assessment systems also moved from product-oriented to process-oriented ones. But still as a result of focusing on wide-spread and commonly used product-oriented testing the reason why some students perform very well in the class but cannot get high grades from the tests or many other details about their learning and test performance remains unclear for teachers because they have no access to the process of taking the test and the only data provided for them by product-oriented testing is the final result of that test.

At this point, dynamic assessment (DA) in language learning can offer new insights into assessment in the language classroom by revealing invaluable secrets about the ability of individual students and their abilities while answering each test item. The reason can be the process-oriented nature of dynamic assessment. While the results of traditional non-dynamic assessment (NDA) can only show the already existent abilities of the student, DA adjusted to the needs of particular learners makes it possible to evaluate the ability of the student to learn from the interaction with a teacher or a more competent peer and predict their possible future development.

The purpose of this study is to reflect the effectiveness of dynamic assessment in fulfilling the main responsibility of education for learners which is finding new routes to one's future development and guiding the individual to higher stages of development based on needs and potentials and in a way unique for each group of learners.

\section{Review of the Related Literature}

\section{Sociocultural Theory}

Dynamic assessment is mainly based on Vygotsky's sociocultural theory of mind which strongly proposes that cognitive development is best understood within its social and cultural contexts. It attempts to account for the processes through which, learning and development take place. Learners need help of another person to perform a new task and then after internalizing it they can perform the task independently. Social interaction, therefore, mediates learning. Sociocultural theory has profound implications for researches about mind, mental development and also educational practices. As Nassaji and Cumming (2000) justly conclude defining the dialogic nature of teaching/learning processes within the zone of proximal development and designing research that exemplifies its nature is central in sociocultural theory. 


\section{Zone of Proximal Development}

Most teachers and parent have experienced the advantage of proper assistance from an adult or a more advanced peer in child's is more and better learning than on his/her own, but it was Vygotsky who for the first time elevated this simple observation to a theoretical generalization known as zone of proximal development (ZPD). According to his theory, children's cognitive development occurs at the potential or assisted level (present to future), and at actual and unassisted level (past to present). At the actual or autonomous level, the child can do the task without any help, but at the potential level the child needs another person's (a mediator's) assistance (Vygotsky, 1986, 1978). He suggested that the process of scaffolding brings about abilities that have been in the process of emerging, developing, (that is, have not yet matured) and consequently reveals the hidden potential of a child which is vital in not only diagnosis but also prognosis. ZPD in fact refers to the range of tasks that a child can complete unaided and independently and those completed with the guidance and assistance of an adult or a more capable peer. Vygotsky himself (1978, p: 24) defines zone of proximal development as:

The distance between the actual developmental level as determined by independent problem solving and the level of potential development as determined through problem solving under adult guidance or in collaboration with more capable peers.

Roosevelt (2008) concludes that from Vygotskian perspective the main goal of education is keeping learners in their own ZPDs as often as possible by giving them interesting and culturally meaningful learning and problem-solving tasks that are slightly more difficult than their current ability or what they can do alone, so that they will need to work with a more competent peer or a teacher or an adult to complete the task. After this jointly completion of task, the learner will likely be able to do the same task individually and independently next time, so the learner's ZPD for that particular task will have been raised. This process is then done for an even more difficult task appropriate for the learner's new ZPD.

In terms of language learning, Williams et al. (1997) parallelize ZPD with interlanguage. It conceives that each learner's understanding of the language system is gradually reshaped as it develops and more closely approximates towards the target language system. So the ZPD can be seen as the next level of understanding in the learner's interlanguage. The notion of ZPD interpreted this way aims at directing attention to the idea that instruction and assessment should be based on maturing rather than matured abilities which was the basis of several instructional programs such as dynamic assessment (DA).

\section{Dynamic Assessment}

Dynamic assessment in language learning, which derives from Vygotsky's (1986, 1978) idea on how child's cognition develops and applies Vygotsky's sociocultural theory into assessment, can offer new insights into assessment in the language classroom by revealing invaluable secrets about the ability of individual students and their abilities while answering each test item. The reason can be the processoriented nature of dynamic assessment. While the results of non-dynamic 
assessment can only show the already existent abilities of the student, the analysis of ZPD makes it possible to evaluate the ability of the student to learn from the interaction with a teacher or a more competent peer.

To emphasize the fluid nature of dynamic assessment Lidz (1987, p.4) define it as "an interaction between an examiner-as-intervener and a learner-as-active participant, which seeks to estimate the degree of modifiability of the learner and the means by which positive changes in cognitive functioning can be induced and maintained." According to Lantolf and Thorne (2006, p.28), Vygotsky argued that "the only appropriate way of understanding and explaining ... forms of human mental functioning is by studying the process, and not the outcome of development". This is the critical point which distinguishes dynamic assessment from non-dynamic assessment. Murphy (2011, p.1) sees DA as "an approach to understanding and conceiving an individual in the assessment process."

DA provides information crucial for effective remediation, which is the ultimate goal of this assessment and is not provided by traditional non-dynamic tests. Lidz (1995) observed that traditional standardized assessment trails the learner's cognitive development to the point of "failure" in his/her independent functioning, whereas DA leads the child to the point of achieving success in mediated performance because it aims at identifying obstacles to more effective leaning and performance, to find ways to overcome those obstacles on subsequent learning and performance effectiveness (Haywood \& Lidz, 2007, p.3). The assumption behind dynamic assessment is that some individuals can achieve much more cognitively if provided the opportunity to work with a 'significant other' to improve their cognitive efficiency. The aim of, dynamic assessment is to optimize cognitive functioning, rather than simply to sample it, and it is here that a paradigm shift in intellectual assessment occurs (Grigorenko \& Sternberg, 1998, p. 77; Lidz, 1997, p. 291).

An important advantage of DA is making recommendations based on developmental potential which is not revealed by traditional non-dynamic tests (Davin, 2011). In dynamic assessment the learners are instructed on how to perform certain tasks, and mediated assistance on how to master them are provided. Their progress in the ability to solve similar problems is then measured (Kirchenbaum, 1998). Lidz (1987) views dynamic assessment as an interaction between an examineras-intervener and a learner-as-active participant, which seeks to estimate the degree of modifiability of the learner and the means by which positive changes in cognitive functioning can be induced and maintained. He defines dynamic assessment as:

approaches to the development of decision-specific information that most characteristically involve interaction between the examiner and examinee, focus on learner metacognitive processes and responsiveness to intervention, and follow a pre-test-intervention- post-test administrative format. (1997, p. 281)

DA aims at assessing the learner's at times hidden potential or reserve capacity in a dynamic, process - oriented, and flexible way in which assistance or mediation is provided by instruction and feedback for cognitive skill acquisition (Campbell \& Carlson, 1995 ; Elliott, 2003 ; Gillam \& McFadden, 1994; Grigorenko \& 
Sternberg, 1998 ; Kirkwood, Weiler, Bernstein, Forbes \& Waber, 2001 ; Kirschenbaum, 1998 ; Kliegl, Smith \& Baltes, 1989; Lidz, 1997; Meyers, 1987; Minick, 1987; Sternberg \& Grigorenko, 2002 ). The rationale behind this method of assessment is that if a learner can improve on initial performance when mediated, s/he has the potential to achieve more (Ukrainetz, Harpell, Walsh \& Coyle, 2000). DA is generally based on the belief that assessment of an individual's present knowledge is not nearly as revealing as an assessment of that individual's potential so in dynamic assessment determining potential performance is more emphasized than assessing typical performance.

All proponents of dynamic assessment recognize that people usually function at levels far below their capacity so assessment of their present performance in invaluable in predicting their future performance. To assess the possibilities in optimal conditions and defeat pessimistic predictions derived from non-dynamic assessment of typical performance a dynamic assessment involving intervention and seeking of potential is required (Haywood \& Lidz, 2007, p.9).

Dynamic assessment has some general characteristics. First, it is administered according to a - test intervention-retest format (Lidz, 1991). Second, the testintervention-retest aspect of dynamic assessment is closely related to the learner's modification. Third, it generates information for developing interventions. Dynamic assessment uses teaching as part of the assessment; it supplies useful information for developing interventions.

To contrast dynamic and non-dynamic assessment Sternberg and Grigorenko (2002, p.vii) define dynamic assessment as a procedure whose outcome

...takes into account the results of an intervention. In this intervention, the examiner teaches the examinee how to perform better on individual items or on the test as a whole. The final score may be learning score representing the difference between pre-test (before learning) and post-test (after learning) scores, or it may be the score on the post-test considered alone.

In formal approaches to non-dynamic assessment, on the other hand,

the examiner presents items, either one at a time or all at once, and each examinee is asked to respond to these items successively, without feedback or intervention of any kind. At some point in time after the administration of the test is over, each examinee typically receives the only feedback he or she will get: a report on a score or set of scores. By that time, the examinee is studying for one or more future tests (Sternberg and Grigorenko, 2002, p.vii).

Offering individuals an opportunity to learn, dynamic assessment has the potential to show important information about individual strategies and processes of learning. In other words, dynamic assessment sees development process as a predictor of the test-taker's future performance and offers potentially useful suggestions about teaching, because it measures the processes of knowledge acquisition at the time of test. It sees language learning as knowledge construction and the outcome of interaction between student and teachers (Birjandi, Daftarifard, \& Lange, 2011). Dynamic assessment enhances our understanding of individuals' abilities. The 
mediation through dynamic assessment helps learners to reconsider and think through problems and better enable the mediator to identify the learners' understanding to relevant linguistic features. Its emphasis on instruction and intervention within the assessment procedure is the result of individualized view of dynamic assessment toward instruction and assessment in which individual differences are identified and appropriate actions are taken for each learner based on his/her own ZPD. In non-dynamic procedure; however, important differences among learners are often masked.

For Vygotsky, abilities are not innate but are emergent and dynamic. Through participating in various activities, and through being mediated by those around them, individuals come to master their cognitive functions in unique ways. In DA, the examiner-examinee relationship is thus transformed, with the examiner intervening during the assessment. The conventional "attitude of neutrality" characteristic of NDA "is thus replaced by an atmosphere of teaching and helping" (Sternberg and Grigorenko, 2002, p.29). The reason of using modifiability in dynamic assessment is its grounding in zone of proximal development (ZPD). In fact dynamic assessment insists that a complete assessment should determine the extent of the person's performance modifiability. In formal non-dynamic assessment; however, any change in the person's performance during the assessment is considered as a threat to test reliability. The reason for such consideration is that non-dynamic assessment is rooted in psychometric principles which view any change in testtaker's performance due to interaction a source of pollution and a threat to test reliability.

Proponents of dynamic assessment have long argued that it improves validity because it provides information about individuals' abilities that non-dynamic measures typically do not (Lidz and Elliot, 2000, p: 5). Anton's study (2003) also argue strongly in favor of the validity of dynamic assessment by demonstrating that dynamic assessment procedures is in fact superior to be non-dynamic assessment methodology by revealing important differences among students. In other words, while the scope of non dynamic assessment is just limited to the past learning experience of individuals, dynamic assessment presents a broader scope of past to present experiences and future capabilities, and is therefore able to provide prescriptive information about language learning and any other kind of learning in general. Dynamic assessment requires a different way of thinking about assessment and the abilities being measured. It is based on modern cognitive theories that view abilities and competence as changeable and sensitive to instruction. It assumes that abilities are not static but are in transactional relationships with the world (Haywood \& Lidz, 2007). Learning and change are assumed to take place with experiences, including testing experiences and interactions with others.

Dynamic assessment does not refer to assessment instruments but to administration procedures; in fact any test can be conducted as dynamic or nondynamic. In other words the notion of dynamic assessment does not refer to any particular way of testing or a specific procedure or technique but describes a wide range of methods. It is a tool as well as an approach which assesses learners in a fluid, flexible and process-oriented way (Murphy 2011, p.1). Dynamic assessment and non-dynamic assessment cannot be placed on a single continuum because they 
differ both ontologically and epistemologically. Non-dynamic assessment conceives of assessment and instruction dualistically and is intended to profile, or even measure, abilities in their current state. Dynamic assessment offers a monistic view of assessment and instruction that focuses on developing abilities through intervention (Lidz, 1991, p.6). Lidz and Gindis (2003) believe that these differing philosophies have profound implications for assessment practice. In fact, dynamic assessment is a completely different approach, or an umbrella term (Elliott, 2003),for testing in the language classroom which can be applied to any way of testing ranging from multiple choice to essay writing, for student with different backgrounds from monolingual environments to linguistic diversities (Haney and Evans, 1999; Laing and Kamhi, 2003). But the common misconception among many teachers and researchers is considering portfolio or other alternative assessments as only way of applying dynamic assessment in the language classroom. But in fact these assessments if applied in an interactive way can only be examples of dynamic assessment. So reducing the methodological applications of dynamic assessment into one or some specific testing instruments is misunderstanding the underlying theory of dynamic assessment.

To support this idea Lantolf and Thorne (2006, p.331) state that "what makes a procedure dynamic or not is whether or not mediation is incorporated into the assessment process. In other words, fill-in-the-blank, multiple-choice, open-ended essay, or even oral proficiency tests in themselves may or may not be dynamic. Their status is determined by the goal of the procedure and the format in which it is subsequently administered. In other words, there are no dynamic assessment instruments per se; there are only dynamic assessment procedures." So it is better not to limit the vast area of dynamic assessment to a specific test instruments and have in mind that any test taken interactively can be considered as dynamic. That is to say the core characteristic of widely varying methods of dynamic assessment is their use of an interactive procedure in which the examiner provides guidance, encouragement, and feedback in an attempt to elicit the best performance (Haywood \& Lidz, 2007).

\section{Previous Studies on DA}

Although theoretical framework of dynamic assessment was proposed by Vygotsky, he did not present any methodological guidelines for its application in real educational settings. There is a robust research literature on dynamic assessment in general education and psychology, however, the approach is relatively unknown or at least new in second/foreign language studies.

In fact dynamic assessment has generated an impressive body of research in the study of general intelligence and of basic learning abilities among individuals with special needs (Tzuriel, 2000; Lidz, 2002; Baek, \& Kim, 2003; Hasson, \& Joffe, 2007; Resing, 2009; Wang, 2010;), but studies of dynamic assessment's implications for problems particular to the development of L2 abilities are only beginning by a limited number of scholars in this field. Most of these discussions have been made at the theoretical level of dynamic assessment in language education and the number of studies focusing on practical and empirical dimensions to provide guidelines of methodological applications is very limited. For example Yildirim (2008) takes an in 
depth look at the issue of dynamic assessment from the standpoint of Vygotsky's sociocultural theory. He draws the theoretical framework and also discusses the methodological applications of the theory but his study doesn't include practical and empirical dimension in detail.

Among the limited number of empirical studies is Grigorenko et al.'s research (2000) in which a learning theory called CANAL-F (Cognitive Ability for Novelty in Acquisition of Language (Foreign) was developed. According to this theory, learning including foreign language learning is understood as the ability to cope with novelty and ambiguity ( $p: 392$ ). Based on this theory the researchers developed a formal test that measured the ability of learners to deal with novel problems. They name this test as CANAL-FT. It has different subtests including morphology, semantic and syntax as well. During the test an invented language was introduced to the learners along with some examples of it. The students were then asked to do some tasks in that language. At each stage of the test new information about that language was provided to the learners and their ability in applying this information to continue the tasks was measured. Although any king of mediation or guidance is not provided during the test, the researchers believe that their study is an example of dynamic assessment because it directly measures the amount of learners' language learning during the assessment procedure.

Nassaji and Cumming (2000) aimed to provide a case-study account of features of the ZPD in language teaching and learning. They analyzed 95 exchanges in interactive dialogue journals written over 10 months between a 6-year-old Farsi speaker beginning to learn English and his Canadian teacher and showed how the teacher and student constructed and sustained a long-term written conversation involving intricate patterns of complementary, asymmetrical scaffolding. They emphasize the value of analyzing language learning and teaching as integrally unified, interactive phenomena. Using an analytic scheme that highlights the functional dimensions of interpersonal communication, they showed different patterns in the written exchanges between the teacher and student that sustained in a complementary, dynamic, and evolving manner over nearly a year - conditions for an ESL student's learning English literacy, scaffolded by his teacher. In the process, the learner came to appropriate aspects of English that he personally determined were worth expressing, while the teacher contributed to and edged him forward in this process, engaging with his written accomplishments and the same time herself coming to understand better the student and his personal concerns and abilities. Both acted as proficient users of English - in spite of the student's emergent spellings, vocabulary, syntax and penmanship - because the dialogue journals created a 'setting for thought' (Butterworth, 1993), in which both participants reciprocally shared common knowledge, purposes and tools of communication, evidently understanding and appreciating them.

Lantolf and Aljaafreh (1995) examined the interaction between adult ESL learners and a tutor. Learners progressed in the ZPD through developmentally sensitive assistance in tutoring sessions. The emergence of a ZPD through pair-work resulted in performance at a higher level of competence for both students because a learner performs above his/her level of individual competence in the ZPD with the 
assistance of the peer and as the learner acts with increasing independence development occurs.

One of the well-known studies in DA is Anton's. Anton (2003) in her study applied a dynamic assessment procedure for placement of L2 Spanish undergraduate students. She explains that dynamic assessment is more appropriate for placement purposes because it sheds light on students' developing abilities rather than focusing solely on developed ones which is done by non-dynamic assessment. She believes that using dynamic assessment procedures makes the placement become more accurate because a complete picture of the abilities is presented. So important hidden differences among students become vivid which is a proof of the validity of dynamic assessment.

Anton asked the participants of her study to orally narrate the movie they had watched and her main emphasis was on the correct use of past tense in narrations. She applied interactionist approach by interrupting the narrations to provide hints and guidance whenever needed in order to give them the opportunity to revise their performance in appropriate ways. The researcher presented interesting and useful parts of the protocol to show a vivid picture of what had gone during the assessment session. In another study, Antón (2009) also examined the usefulness of DA with university students. She implemented DA with third year Spanish majors on the speaking and writing portions of a diagnostic test. She concluded that DA resulted in a deeper understanding of students' abilities.

Poehner (2008) in his study on advance level adults learning French as their foreign language played different parts of an English movie to the participants. First, learners constructed an oral narrative in the target language after watching a short video clip, they received no mediation in the first task. Then they were shown a second clip from the same story but this time to improve the speaking ability of these French learning they received hints, leading questions, suggestions, and explicit feedback when constructing their oral narratives. The assessment which focused on the performance differences between the first and second tests were used as the basis for an individualized instructional program in which participants were tutored in areas that had been identified during the dynamic assessment sessions as needing special attention. He also assessed university students' ability to correctly decide between and conjugate the imparfait and passé compose in French when narrating a movie. He offered mediation tailored to the needs of his students in both a near and far transcendence task and concluded that using DA provided insight into the source of students' errors. He concluded that the mediation resulted in improved understanding of these two tenses and aspect for the students.

Another researcher Ableeva (2008) also used DA with university students learning French. She aimed at promoting development of listening comprehension skills and found that the differences in learners' difficulties on an assessment revealed their unique ZPDs, which is not revealed in the non-dynamic pre-test. According to her employing DA in reading and listening comprehension classroom makes it possible for both learners and their teachers to identify the probable sources of problems that might hinder text comprehension.

Birjandi, Daftarifard, and Lange (2011) investigated whether it is possible to distinguish the quantitative and qualitative effects of dynamic assessment on the 
items and persons. They used two types of Rasch scaling to scale sets of wh-type questions and scanning items. The data gathered from 42 Iranian university students showed the anticipated quantitative improvement in learners' performance on the posttest relative to the pretest-for the wh-type questions as well as for scanning items. But clear qualitative effects were not found, because the item and person hierarchies were almost the same for the pre- and post-tests. The rating scale formulation proved to be a useful measure of ZPD as it proved to be a proper tool of capturing the pre- and post-test data simultaneously.

Lantolf and Poehner (2011) examined how a K-5 Spanish teacher implemented dynamic assessment with a large group of students simultaneously. Before this study dynamic assessment was mostly used individually with one mediator and only one learner. They incorporated dynamic assessment into daily lessons without changing instructional objectives or curricular goals by teaching within the ZPD of students to promote development of subject/adjective agreement in Spanish and gained positive results in promoting the group's ZPD.

Xiaoxiao and Yan (2010) in their case study on dynamic assessment of EFL process writing presented a simple framework or a process for English writing instruction based on the principles of dynamic assessment. Results of applying their framework revealed that the dialogic way of teaching is of great help in enhancing learners' writing interest and improving their writing competence.

In a recent study Sadeghi and Khanahmadi (2011) assessed the viability of dynamic assessment used as an instructional adjunct in the development of Iranian EFL learners' grammar. The study was conducted on 60 intermediate EFL learners and each session during the treatment the two groups of experimental and control took a grammar test in which the experimental group received mediation on test items. The results of their study proved that dynamic assessment oriented instruction significantly improved the learning of L2 grammar.

Pishghadam, Barabadi, and Kamrood (2011) applied a computerized dynamic assessment on 104 university students with moderate proficiency level. The software could calculate the non-dynamic assessment score of the participants, that is their score before any intervention of each item, as well as a dynamic assessment score, which is the score after providing mediation for unsuccessful answers. Using a t-test the researchers compared the dynamic and non-dynamic score of the participants and found a significant difference implying the usefulness of dynamic assessment in increasing the reading comprehension score of the participants. These researchers however didn't investigate the amount of transcendence ability of the participants. It would be more appropriate if they had investigated whether the participants could apply the suggested hints and mediations in similar tasks or test items or not because comparing scores merely before and after the mediation cannot imply the learners improved reading comprehension ability.

In another study on dynamic assessment of reading comprehension Naeni and Duvall (2012) used a mixed method to study the improvements in reading comprehension performance of 10 university students by applying the mediation of dynamic assessment approach to instruction and assessment. The mediation phase of their study included three internetion sessions each on one particular reading comprehension subskill among three which were finding the main idea, inference, 
and finding out the meaning of unknown words. Their findings reveal significant improvement in the reading comprehension performance of the participants after the mediation.

Although these researchers presented scripts from the mediation sessions in quanlitative part of their study, the number of extracts all limited and present only a partial picture of the whole process where as the qualitative part of the study by nature requires a deeper presentation of the mediation sessions and a thorough interpretation of the hints and learners reaction to them. The quantitative part of the study is so small in scale that can't be considered as a scientific study. Because comparing the number of correct answers for three reading comprehension sub skills in pre- and post-test of ten participants cannot be so revealing. It would be better if the researchers had increased the number of participants in quantitative part of their study.

Limited number of studies mentioned above with all the promoting results imply that more studies are needed in the field of language learning in order to better understand the effects of dynamic assessment on language learning, and in order to provide more guidance to language teachers who wish to use dynamic assessment in their language classrooms. The present study therefore aimed at filling some part of the gap in dynamic assessment literature by comparing the immediate and delayed effects of dynamic assessment with non-dynamic assessment at different language proficiency levels which has not been investigated in dynamic assessment literature so far. No study has previously investigated the role of proficiency level in dynamic assessment and whether dynamic assessment can have different results for learners with different proficiency levels. Findings about this point can have useful and valuable applications in EFL teaching, testing, syllabus design, and material development. The importance of this issue was the main driving force for this piece of study.

In fact test-takers of different proficiency level may differ in their ability to apply the provided hints in other non-dynamic assessment context. In order to compare and contrast this ability and find out which proficiency group took the greatest advantage of the mediation the following question was presented.

1. Does immediate effect of dynamic assessment differ with proficiency level?

The next research question aimed at investigating such a difference in proficiency level of test-takers in applying the hints in non-dynamic assessment sessions after some time interval. That is to find out whether participants of high-, mid-, and low-proficiency level differed in their ability to use the points during mediation in later non-dynamic sessions and if the answer turned out to be positive which group was more successful in this ability.

2. Does delayed effect of dynamic assessment differ with proficiency level?

According to the mentioned research questions the following research hypotheses were formulated. Confirming or rejecting these hypotheses will lead into answering the main research questions.

1. There is no difference in immediate effect of dynamic assessment on EFL reading comprehension ability of high, mid, and low-proficiency level learners.

2. There is no difference in delayed effect of dynamic assessment on EFL reading comprehension ability of high, mid, and low-proficiency level learners. 


\section{Method}

\section{Participants}

197 male and female Iranian university students with different proficiency levels participate in this study. Some of them were undergraduate students majoring English Literature, English Translation, Teaching English as a Foreign Language (TEFL), and agricultural Engineering. The others were master students in Midwifery, Nursing, and Neonatal Intensive Care Nursing (NICU). The participants were all in their autumn semester taking reading 1, reading 3, general English, and English for specific purposes (ESP) courses. The sampling was convenience sampling because the participants of experimental groups were taken from intact classes for which the researcher herself was the teacher. Also the nature of the selected courses could let the researcher conduct the study and gather the data without interfering with the curriculum and wasting students' class time. Because of the limitation in teaching hours of each instructor the researcher had to select some of the participants of the control group from similar courses of the colleagues. With permission of the colleagues the researcher herself was in classes during test administration in control groups to make sure that the procedure was constant for all the groups.

Due to ethical issues the students were informed to be included in research study. The general aim of the study was explained to the participants in experimental group to reduce the stress during the assessment sessions and prevent any cheating or guessing the answer for a better score. The researcher didn't go into details of purposes to prevent the sources of data pollution such as Hawthrone effect. Brown (1988, p. 32) believes that "it is possible for the subjects to be pleasant at being included in a study that the results of the investigation are more closely related to this pleasure than to anything that actually occurs in the research". Since the research procedures were in line with course objectives and also didn't require any out of class time devotion the students were all eager to take part in the study.

\section{Instruments}

To gather the data needed for the study the researcher applied two different data gathering instruments at various stages of the study including an international proficiency test and standardized reading comprehension tests.

Proficiency test. A 90-item BPT TOEFL test was used to measure the proficiency level of the participants. TOEFL tests are among the most common and standardized EFL proficiency tests worldwide and the researcher wouldn't doubt their validity and reliability.

Reading comprehension tests. 9 reading comprehension tests each including a passage followed by 20 multiple-choice questions were used for pretests, immediate posttests and delayed posttests of the groups in three proficiency levels of high, mid, and low. The tests were taken from books published by National Organization for Educational Testing which holds national university entrance exams in Iran. The questions were taken from these series to solve the problem of test validity and reliability. The total number of items in some cases exceeded 20 but 
to have consistency in the procedures the researcher omitted the extra questions to have a fixed number of 20 items for all tests. To prevent any kind of bias the omitted items were selected randomly before reading the questions.

\section{Procedures}

Participants were asked to take part in the PBT TOEFL test which served as a placement test to group the participants into three proficiency levels of high, mid, and low. The students were classified in these groups according to their proficiency scores but unfortunately it was not possible to group them together in different classes, because the students were from different universities, different majors, and also different courses. The General English proficiency level of Iranian students varies greatly in university classes because of poor performance of school curriculum on English language and attendance of some students to conversation courses of open institutes, however, the number of students living in English speaking countries for an extended period of time is usually very limited.

The researcher tried to overcome all these problems by preparing different pre-test, post-test and quiz questions for each group. So the classmates had to answer different reading comprehension items based on their proficiency level. Fortunately this didn't cause a problem for the research procedures because the tests were written not oral and the participants answered the item individually not in pairs or groups and also to prevent any error or confusion the researcher classified the papers and scores in related proficiency level folders just the same day after correcting the papers.

After determining the proficiency level of each participant, the learners in each proficiency level were divided into two groups of control and experimental. Due to some problems mentioned earlier the researcher couldn't specify control and experimental groups randomly. Because she wanted to apply the procedures herself, she selected the learners in her own classes as experimental and the ones in colleagues' groups as control. This might be considered as a limitation of the study but she couldn't find any other solution. Since the colleagues were not familiar with the nature of correct mediation in dynamic assessment, specifying some of the experimental participants to their groups would probably lead into affective support or task-completion support, instead of development-support, and that would ruin the whole study. Table 1 presents the frequency of each study group.

Table 1

Frequency of Groups

\begin{tabular}{|l|l|l|}
\hline Independent variables & Levels & $\mathrm{N}$ \\
\hline \multirow{3}{*}{ Proficiency level } & Low proficiency & 66 \\
\cline { 2 - 3 } & Mid proficiency & 67 \\
\cline { 2 - 3 } & High proficiency & 64 \\
\hline \multirow{2}{*}{ Study groups } & Experimental & 99 \\
\cline { 2 - 3 } & Control & 98 \\
\hline
\end{tabular}


After dividing the participants into 6 groups of experimental and control in three high-, mid-, low-proficiency levels the next session they were given their pretests. These tests were conducted in non-dynamic way as Iranian students were familiar with. While the participants in three control groups continued their normal class procedures until the post tests the participants of experimental group underwent 5 dynamic assessment sessions before the post-tests. Each assessment was done in separate weeks and to meet the conditions of dynamic assessment the researcher did her best to provide the necessary assistance and guidance appropriate for test-takers' ZPD in three proficiency groups of high, mid, and low. Due to large number of students in classes and their different proficiency level it was not possible to apply interactionist model of dynamic assessment that is to have mediated dialogues with individual participants to provide the needed support for their development. The selected model for this part of data collection procedure was, therefore, interventionist approach. That is the mediator, also the researcher in this study, provided the same hints for all learners but to adjust it to their ZPD the hints were provided from the most implicit to the most direct and explicit. The total number of hints was three for each test item and since the speed of individuals and also their level proficiency in each class differed the researcher provided the hints as written mediation forms. The number of test item was identified in these forms, and under each item three hints were presented as A, B, and C. To have consistency between groups the hints were presented in Persian, the official language of Iran, because it would be impossible to have English hints for low level participants. The students had to write their names on top of these forms and check the hints they had used. This would specify which hints were useful for each participant. If the testtaker couldn't answer the item correctly after reading all the three hints it would mean that the scope of the question is beyond his/her ZPD. That is that ability is neither developed nor developing in cognitive system of the individual so neither of independent or collaborated performance is possible at that time. If the hints helped them to answer the item it was concluded that the ability was developing for them.

To see whether the dynamic assessment procedure led into any development in participants, they took part in the first post-test. The post test was for all the participants. The questions were different for each proficiency level and the procedures were non-dynamic. To observe the effect of dynamic assessment and to make the scores as reliable as possible the researcher avoided any help in that test session and the test takers of experimental group had to resort to their previous experience of taking dynamic test and get help of the key points of those sessions and show how much they had learned from those dynamic session. Students in control group took the test as usual because they were already familiar with and used to non dynamic tests. To realize which proficiency level took the greatest advantage of immediate effect of dynamic tests a comparison was made between three proficiency levels of experimental groups.

But the study was not limited to this point and another new step in the related literature was taken. To find out the delayed effect of dynamic tests in different proficiency groups, test takers were called for the second test after five weeks to measure their ability in transferring the developed abilities into new items after some time, and the same testing procedure. 


\section{Design of the Study}

The present study included pre-test and post-test as well as control and experimental groups. But since the selection of the two groups (control and experimental) couldn't be done randomly due to the limitations explained in the procedures section the design of this study was quasi-experimental. The study included two categorical independent variables which were study group with two levels of control and experimental and proficiency level with three levels of low, mid and high. There were also three interval dependent variables in this study; that is reading comprehension scores in pre-test, immediate post-test, and delayed post-test. For this $2 * 3 * 3$ design a MANOVA was applied for making comparisons between 6 study groups at the beginning of the study, just after the mediation, and after some time interval.

\section{Findings}

This study included 2 study groups of experimental and control at three low, mid, and high-proficiency levels, each taking 3 pre-test, immediate post-test, and delayed post-test reading comprehension tests. All of these mean scores along with their standard deviations and the number of participants in each group are presented in Table 2.

Table 2

Descriptive Statistics of Groups

\begin{tabular}{|c|c|c|c|c|c|}
\hline Test & Proficiency level & Study group & Mean & SD & $\mathrm{N}$ \\
\hline \multirow{8}{*}{ Pre-test } & \multirow{2}{*}{ Low proficiency } & Experimental & 12.94 & 3.946 & 34 \\
\hline & & Control & 13.03 & 4.020 & 32 \\
\hline & \multirow{2}{*}{ Mid proficiency } & Experimental & 13.28 & 4.692 & 32 \\
\hline & & Control & 12.63 & 4.479 & 35 \\
\hline & \multirow{2}{*}{ High proficiency } & Experimental & 13.00 & 4.093 & 33 \\
\hline & & Control & 13.81 & 4.708 & 31 \\
\hline & \multirow{2}{*}{ Total } & Experimental & 13.07 & 4.207 & 99 \\
\hline & & Control & 13.13 & 4.392 & 98 \\
\hline \multirow{6}{*}{$\begin{array}{l}\text { Immediate } \\
\text { post-test }\end{array}$} & \multirow{2}{*}{ Low proficiency } & Experimental & 16.18 & 2.222 & 34 \\
\hline & & Control & 13.00 & 3.802 & 32 \\
\hline & \multirow{2}{*}{ Mid proficiency } & Experimental & 16.53 & 2.639 & 32 \\
\hline & & Control & 12.83 & 4.737 & 35 \\
\hline & \multirow{2}{*}{ High proficiency } & Experimental & 16.88 & 2.643 & 33 \\
\hline & & Control & 13.45 & 3.632 & 31 \\
\hline
\end{tabular}




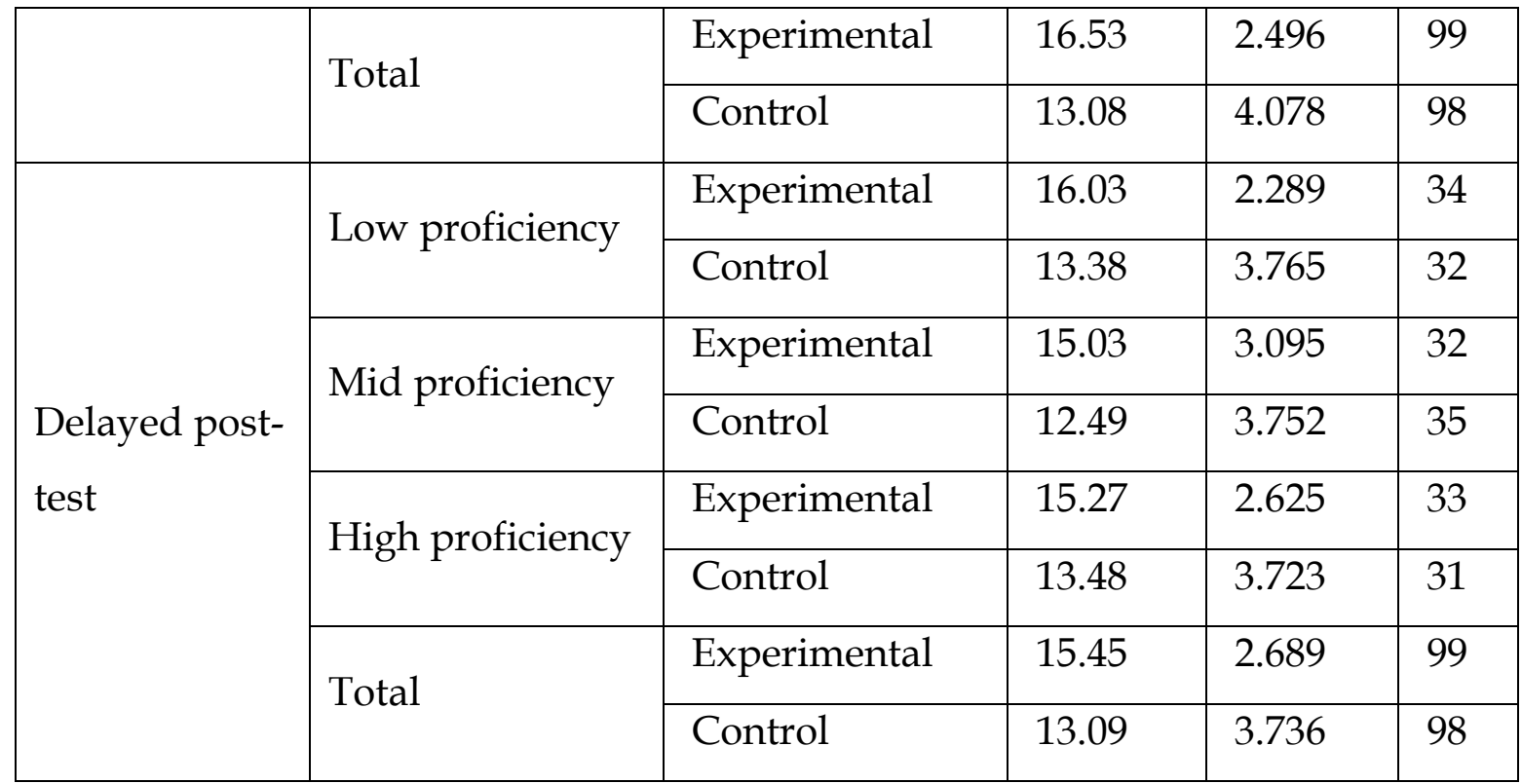

In order to find out the immediate and delayed effect of dynamic assessment in three proficiency levels a MANOVA was used because there were two categorical independent variables: study group and proficiency level. There were also three interval dependent variables: pre-test, immediate port-test, and delayed post-test of reading comprehension. The results of the statistical analyses are presented in Table 3.

Table 3

The Effect of DA on Study Groups of Different Proficiency Levels

\begin{tabular}{|c|c|c|c|c|c|c|c|}
\hline Effect & $\begin{array}{l}\text { Statistic } \\
\mathrm{S}\end{array}$ & Value & $\mathrm{F}$ & $\begin{array}{l}\text { Hypothesis } \\
\text { df }\end{array}$ & $\begin{array}{l}\text { Error } \\
\text { df }\end{array}$ & Sig. & $\begin{array}{l}\text { Partial eta } \\
\text { squared }\end{array}$ \\
\hline Study group & $\begin{array}{l}\text { Wilks' } \\
\text { Lambda }\end{array}$ & .583 & $\begin{array}{l}45.14 \\
1\end{array}$ & 3.000 & $\begin{array}{l}189.00 \\
0\end{array}$ & $\begin{array}{l}.00 \\
0\end{array}$ & .417 \\
\hline $\begin{array}{l}\text { Proficiency } \\
\text { group }\end{array}$ & $\begin{array}{l}\text { Wilks' } \\
\text { Lambda }\end{array}$ & .961 & 1.251 & 6.000 & $\begin{array}{l}378.00 \\
0\end{array}$ & $\begin{array}{l}.27 \\
9\end{array}$ & .019 \\
\hline $\begin{array}{l}\text { Study } \\
\text { group* } \\
\text { Proficiency } \\
\text { group }\end{array}$ & $\begin{array}{l}\text { Wilks' } \\
\text { Lambda }\end{array}$ & .985 & .464 & 6.000 & $\begin{array}{l}378.00 \\
0\end{array}$ & $\begin{array}{l}.83 \\
5\end{array}$ & .007 \\
\hline
\end{tabular}

As shown in Table 3, there was a significant difference between reading comprehension score of the control and experimental groups: $\mathrm{F}(3,189)=45.141, \mathrm{P}<$ 0.05.; Wilks' Lambda $=.583$; Partial eta squared $=.417$. But there was not a significant difference among proficiency levels: $\mathrm{F}(6,378)=1.251, \mathrm{P}=.279$; and the interaction of study groups and proficiency groups didn't cause a difference in reading 
comprehension scores either: $\mathrm{F}(6,378)=.464, \mathrm{P}=.835$. For further analysis the reading scores of control and experimental groups were compared in pre-test, immediate post test and delayed post-test through multiple comparisons. The results of these comparisons are presented in Table 4.

Table 4

Multiple Comparisons for Experimental and Control Groups

\begin{tabular}{|c|l|c|c|c|c|}
\hline \multicolumn{2}{|c|}{ Source } & df & F & Sig. & Partial eta squared \\
\hline \multirow{3}{*}{$\begin{array}{c}\text { Study } \\
\text { Groups }\end{array}$} & Pre-test & 1 & 0.017 & .895 & .000 \\
\cline { 2 - 6 } & $\begin{array}{l}\text { Immediate post- } \\
\text { test }\end{array}$ & 1 & 50.175 & .000 & .208 \\
\cline { 2 - 6 } & Delayed post-test & 1 & 25.175 & .000 & .116 \\
\hline
\end{tabular}

As shown in Table 4, when the results for the dependent variables were considered separately, the difference of experimental and control study groups in the pre-test didn't reach a significant difference at the Bonfertoni adjusted alpha level of 0.017. Bonfertoni adjustment involves setting a more stringent alpha level for each comparison, to keep the alpha across all the tests at a reasonable level. To achieve this, the alpha level (which was 0.05 in this study) was divided by the number of comparisons (which was 3 in this study) and 0.017 was the new alpha level to prevent Type I errors.

The difference of study groups in the immediate post-test reached a significant difference. $\mathrm{F}(1,191)=50.175, \mathrm{P}<0.05$, partial eta squared $=.21$ which according to Cohen's (1988) guidelines is a large effect. Eta squared represents the proportion of variance of the dependent variable that is explained by the independent variable. Values for eta squared can range from 0 to 1 . Cohen (1988) presented the following guidelines for interpreting the strength of eta squared values: $0.01=$ small effect, $0.06=$ moderate effect and $0.14=$ large effect.

An inspection of the mean scores indicated that experimental group had higher reading scores in the immediate post-test $(\mathrm{M}=16.53, \mathrm{SD}=2.5)$ than control group $(M=13.08, S D=4.1)$. The difference of study groups in the delayed post-test also reached a significant difference. $\mathrm{F}(1,191)=25.175, \mathrm{P}<0.05$, partial eta squared $=$ .12 which is again a large effect. An inspection of the mean scores indicated that experimental group had higher reading scores in the immediate post-test $(\mathrm{M}=15.45$, $\mathrm{SD}=2.7)$ than control group $(\mathrm{M}=13.09, \mathrm{SD}=3.7)$.

So neither of the null hypotheses indicating that "There is no difference in immediate effect of dynamic assessment on EFL reading comprehension ability of high, mid, and low-proficiency level learners." and "There is no difference in delayed effect of dynamic assessment on EFL reading comprehension ability of high, mid, and low-proficiency level learners." are rejected and it is inferred that although dynamic assessment has immediate and delayed effect on EFL reading comprehension ability of EFL learners, there is no difference in its immediate and delayed effect among learners with different proficiency levels. 


\section{Discussion and Conclusion}

The present study aimed at investigating the immediate and delayed effect of dynamic assessment on reading comprehension ability of EFL learners at three proficiency levels. The results of the study revealed that while applying dynamic assessment had both immediate and delayed effect on improving the reading comprehension of the EFL learners, no significant difference was observed among different proficiency levels. In other words there is no significant difference in the immediate and delayed effect of dynamic assessment of EFL learners' reading comprehension ability in low-, mid-, and high-proficiency levels. That is to say dynamic assessment can be beneficial for EFL readers and its effect remains over time. And learners of low-, mid-, and high-proficiency levels improve their reading comprehension ability almost equally and the proficiency level doesn't affect the amount of taking the advantage of dynamic assessment.

The findings of this study about the effect of dynamic assessment on reading comprehension ability of EFL learners are in line with the results of previous studies in the literature for example Kozulin and Grab (2002), Poehner (2008), Albbeva (2008), Birjandi, et al. (2011), Pishghadam, et al. (2011), and Naemi and Duvall (2012). But the results about the equal advantage of dynamic assessment for learners of different proficiencies were found for the first time and there were no similar studies in the related literature. Dynamic assessment with its emphasis on appropriate interaction and mediation of the assessor with the learner in his/her ZPD aims at finding the limitations and hindering factors in development process and removing them as much as possible and appropriate in that ZPD and tries to move the learner a step further in the process of learning so it seems quite logical that the reading ability of the EFL learners in experimental group of this study increased significantly after applying the dynamic assessment. But the main point to keep in mind is that the function of dynamic assessment is far beyond mere imitation. Since the mediations in dynamic assessment not only should be at the appropriate level according to the test-takers' ZPD but also should be standard, meaningful, and purposeful aimed at only learner development and as Poehner (2008) mentions any kind of mediation for supporting the test-takers affectively or even supporting them just for performing a specific task without showing them the appropriate strategies or teaching them the key points about that task cannot be considered as the mediation intended by dynamic assessment That is why dynamic assessment does not try to help learners perform a task but its goal is that learners learn task performance by the help of mediator and be able to transfer the acquired ability later to other similar tasks in independent performance and reach autonomy. If this kind of autonomy is not reached it can be concluded that the mediation has not resulted in development and was not useful. The findings of the present study showed that EFL learners could gain that kind of development in reading ability because after going through dynamic assessment session and being given the appropriate mediation they were able to take the advantage of the mediations in their later independent performance in immediate post-test. As seen in other research findings many interventions of experimental studies proved to be useful in the post-test but the effect was unfortunately temporary and when investigating the delayed effect it was shown that the effect had faded away so the procedures couldn't be useful in 
long term. But the results of this study showed that the positive and beneficial effect of dynamic assessment remained over time and was not limited to a short period of time after the mediation. The reason again lies in the development-oriented nature of the dynamic assessment. Dynamic assessment tries to make permanent changes in the behavior of the learners which leads into their development. So, as expected such a deeply rooted change or development does not vanish by time.

One other distinguishing feature of the dynamic assessment is its individualized vision toward learning. That is while non-dynamic assessment tries to compare the performance or learning of each learner with other learners, dynamic assessment compares the present performance of each individual with his/her previous performance and make inferences about improvement on such a basis. So it aims at moving the learner further and improving the performance of each individual a stage above his/her current level of ability. Dynamic assessment with its monistic view toward teaching and testing can be seen as a one-way road taken by all the learners no matter what their present level of performance is, and each person takes the advantage of the procedure and moves forward as much as the ZPD allows him/her. It can be concluded that regardless of the proficiency level if correct mediation appropriate to the person's ZPD is provided no one remains unaffected and each learner's ability no matter what his/her proficiency level is improves through dynamic assessment. Another interesting point to be investigated in future studies of dynamic assessment can be comparing low and high achievers' taking advantage of dynamic assessment. 


\section{References}

Ableeva, R. (2008). The effects of dynamic assessment on L2 listening comprehension. In J. P. Lantolf, \& M. E. Poehner (Eds.), Sociocultural theory and the teaching of second languages (pp. 57-86). London: Equinox.

Anton, M. (2003). Dynamic assessment of advanced foreign language learners. Paper presented at the American Association of Applied Linguistics, Washington, D. C.

Antón, M. (2009). Dynamic assessment of advanced second language learners. Foreign Language Annals, 42(3), 576-598.

Baek, S. G, \& Kim K. J. (2003). The effect of dynamic assessment based instruction on children's learning. Asia Pacific Education Review, 4(2), 189-198.

Birjandi, P., Daftarifard, P., \& Lange, R. (2011). The effects of dynamic assessment on Rasch item and person hierarchies in second language testing. International Journal of Language Studies, 5, 125-140.

Brown, J. D. (1988). New ways of classroom assessment. TESOL Publications.

Campbell, C., \& Carlson, J. S. (1995). The dynamic assessment of mental abilities. In J. S. Carlson (Ed.), European contributions to dynamic assessment (vol. 3, pp. 131). London: JAI Press.

Cohen, J. (1988). Statistical power analysis for the behavioral sciences. Hillsdale, NJ: Erlbaum.

Davin, K. J. (2011). Group dynamic assessment in early foreign language learning program: Tracking movement through the zone of proximal development (Doctoral dissertation). University of Pittsburg, US.

Elliott, J. (2003). Dynamic assessment in educational settings: Realizing potential. Educational Review, 55, 15-32.

Gillam, R., \& McFadden, T. U. (1994). Redefining assessment as a holistic discovery process. Journal of Childhood Communication Disorders, 16(1), 36-40.

Grigorenko, E. L., \& Sternberg, R. J. (1998). Dynamic testing. Psychological Bulletin, 124(1), 75-111.

Grigorenko, E. L., Sternberg, R. J., \& Ehrman, M. E. (2000). A theory-based approach to the measurement of foreign language learning ability: The CANAL-FT theory and test. The Modern Language Journal, 84, 390-405.

Haney, M. R., \& Evans, J. G. (1999). National survey of school psychologists regarding use of dynamic assessment and other nontraditional assessment techniques. Psychology in the Schools, 36, 295-304.

Hasson, N., \& V. Joffe. (2007). The case for dynamic assessment in speech and language therapy. Child Language Teaching and Therapy, 23(1), 9-25.

Haywood, H. C., \& Lidz, C. S. (2007). Dynamic assessment in practice: Clinical and educational applications. Cambridge: Cambridge University Press.

Kirschenbaum, R. J. (1998). Dynamic assessment and its use with underserved gifted and talented populations. Gifted Child Quarterly, 42(3), 140-7.

Kirkwood, M. W., Weiler, M. D., Bernstein, J. H., Forbes, P. W., \& Waber, D. P. (2001). Sources of poor performance on the Rey - Osterrieth complex figure test among children with learning difficulties: A dynamic assessment approach. Clinical Neuropsychologist, 15(3), 345-356. 
Kliegl, R., Smith, J., \& Baltes, P. B. (1989). Testing-the-limits and the study of adult age differences in cognitive plasticity of a mnemonic skill. Developmental Psychology, 25(2), 247-256.

Kumaravadivelu, B. (2006). Understanding language teaching: From method to postmethod. New Jersey: Lawrence Erlbaum.

Laing, S. P., \& Kamhi, A. (2003). Alternative assessment of language and literacy in culturally and linguistically diverse populations. Language, Speech, and Hearing Services in Schools, 34, 44- 55.

Lantolf, J. P., \& A. Aljaafreh. (1995). Second language learning in the zone of proximal development: A revolutionary experience. International Journal of Educational Research, 23(7), 619-632.

Lantolf, J. P., \& Poehner, M. (2011). Dynamic assessment in the classroom: Vygotskian praxis for L2 development. Language Teaching Research, 15(11), 1133.

Lantolf, J. P., \& Thorne, S. L. (2006). Sociocultural theory and the genesis of second language development. Oxford: Oxford University Press.

Lidz, C. S. (Ed.). (1987). Dynamic assessment: An interactional approach to evaluating learning potential. NY: Guilford Press.

Lidz, C. (1995). Dynamic assessment and the legacy of L. S. Vygotsky. School Psychology International, 16(2), 143-153.

Lidz, C. S. (1997). Dynamic assessment approaches. In D. S. Flanagan, J. L. Genshaft, \& P. L. Harrison (Eds.), Contemporary intellectual assessment (pp. 281-296). New York: The Guilford Press.

Lidz, C. S. (2002). Mediated learning experience (MLE) as a basis for an alternative approach to assessment. School Psychology International, 23(1), 68-84.

Lidz, C., \& Elliott, J. (Ed.) (2000). Dynamic assessment: Prevailing models and applications. Oxford: Elsevier Science.

Lidz, C. S., \& Gindis, B. (2003). Dynamic assessment of the evolving cognitive functions in children. In A. E. Kozulin, J. S. Brown, S. M. Miller, C. Heath, B. Gindis, \& V. S. Ageyev (Eds.), Vygotsky's educational theory in cultural context (pp. 99-116). Cambridge, UK, New York: Cambridge University Press.

Meyers, J. (1987). The training of dynamic assessors. In C. S. Lidz (Ed.), Dynamic assessment: An interactional approach to evaluating learning potential (pp. 403-25). New York: Guilford Press.

Minick, N. (1987). Implications of Vygotsky's theory for dynamic assessment. In C. Lidz (Ed.), Dynamic assessment: An interactional approach to evaluating learning potential (pp. 116-140). New York: Guilford Press.

Murphy, R. (2011). Dynamic assessment, intelligence and measurement. London: WileyBlackwell.

Naeni, J., \& Duvall, E. (2012). Dynamic assessment and the impact on English language learners' reading comprehension performance. Language Testing in Asia, 2(2), 1-22.

Nassaji, H., \& Cumming, A. (2000). What is in a ZPD? A case study of a young ESL student and teacher interacting through dialogue journals. Language Teaching Research, 4(2), 95-121. 
Pishghadam, R., Barabadi, E., \& Kamrood, A. M. (2011). The differing effect of computerized dynamic assessment of L2 reading comprehension on high and low achievers. Journal of Language Teaching and Research, 2(6), 1353-1358.

Poehner, M. E. (2008). Dynamic Assessment: A Vygotskian approach to understanding and promoting second language development. Berlin: Springer Publishing.

Sadeghi, K., \& Khanahmadi, F. (2011). Dynamic assessment of 12 grammar of Iranian EFL learners: The role of mediated learning experience. International Journal of Academic Research, 3(2), 931-936.

Sternberg, R. J., \& Grigorenko, E. L. (2002). Dynamic testing. The nature and measurement of learning potential. Cambridge: Cambridge University Press.

Resing, W. C. M., Frankje, E. T., \& Tirza Bosma, M. J. (2009). Dynamic testing in indigenous and ethnic minority children. Learning and Individual Differences, $19,445-450$.

Roosevelt, F. D. (2008). Zone of proximal development. Encyclopedia of educational psychology. SAGE publication.

Tzuriel, D. (2000). Developmental perspectives of mediated learning experience theory. In A. Kozulin, \& Y. Rand (Eds.), Experience of mediated learning: an impact of Feuerstein's theory in education and psychology (pp. 217-39). Amsterdam: Pergamon.

Ukrainetz, T. W., Harpell, S., Walsh, C., \& Colye, C. (2000). A preliminary investigation of dynamic assessment with native American kindergartners. Language, Speech and Hearing Services in Schools, 31(2), 142-54.

Vygotsky, L. S. (1978). Mind in society: The development of higher psychological processes. Cambridge: Harvard University Press.

Vygotsky, L. S. (1986). Thought and language. Cambridge: The MIT Press.

Wang, T. H. (2010). Web-based dynamic assessment: Taking assessment as teaching and learning strategy for improving students' e-learning effectiveness. Computers and Education, 54, 1157-1166.

Williams, M., \& Burden, R. (1997). Psychology for language teachers, a social constructivist approach. UK: Cambridge University Press.

Xiaoxiao, L., \& Yan, L. (2010). A case study of dynamic assessment in EFL process writing. Chinese Journal of Applied Linguistis, 33(1), 24-40.

Yildirim, A. G. O. (2008). Vygotsky's sociocultural theory and dynamic assessment in language learning. Anadolu University Journal of Social Sciences, 8(1), 301-308. 